Conclusion: Most of the deceased men and women had cardiovascular and respiratory diseases. There were no statistically significant differences registered in the structure of mortality by gender for all classes of diseases.

Disclosure of Interests: None declared.

DOI: 10.1136/annrheumdis-2021-eular.3436

\section{AB0622 WHEN OSTEOPOROSIS, COELIAC DISEASE AND MULTIPLE MYELOMA CO-EXIST}

S. Khalid ${ }^{1}$, R. Smith ${ }^{1} .{ }^{1}$ Salisbury District Hospital, Rheumatology, Salisbury, United Kingdom

Background: Secondary causes of bone loss are sometimes overlooked in patients who are diagnosed as having osteoporosis. This is especially true if more than one risk factor for secondary osteoporosis is present, with clinicians focusing on the more common cause. Here we present a case of secondary osteoporosis caused by coeliac disease and multiple myeloma.

Objectives: Secondary osteoporosis should be suspected in patients with very low bone mineral density and those with no obvious risk factors. Comprehensive examination and investigations must be done to look for all secondary causes because sometimes, as seen in our patient, you may find more than one.

Methods: A 74 year old gentleman presented to the rheumatology clinic for assessment of osteoporosis. He had been recently diagnosed with coeliac disease. DXA scan showed a T score of -3.5 at the lumbar spine, -2.5 at the left hip and a low Z score of -2.9 . He had not sustained any fractures in the past. There was no history of corticosteroid exposure and no parental history of hip fracture or osteoporosis. He drank up to 21 units of alcohol a week and was an ex-smoker. He was managing a gluten-free diet. His testosterone and vitamin $\mathrm{D}$ levels were normal. Serum electrophoresis, done as part of the osteoporosis workup, revealed a diagnosis of multiple myeloma. He then developed back pain and given his new diagnosis of myeloma, prompt investigations were carried out. A skeletal survey showed T7 fracture and a subsequent MRI scan showed impending cord compression, which were treated successfully with radiotherapy. He underwent chemotherapy and autologous stem cell transplantation for his myeloma.

He recently had an OGD following one week post gluten rechallenge after an established gluten free diet. His biopsy shows no evidence of coeliac disease. Interestingly, the stem cell transplantation did not only treat our patient's myeloma, but also his coeliac disease.

Results: Z-score is a useful indicator of possible secondary osteoporosis. A score of -2.0 or less is below the expected range for age and should prompt careful scrutiny for an underlying cause.

Coeliac disease is a gluten-sensitive enteropathy and a known cause for secondary osteoporosis. It likely causes bone loss by secondary hyperparathyroidism from vitamin $D$ deficiency. Multiple myeloma is a disease of aging adults resulting in osteolytic and/or osteoporotic bone disease through increased bone resorption and decreased bone formation from pro-inflammatory cytokines. While coeliac disease patients are at increased risk of all malignancies, association with multiple myeloma is rare, but has been described.

Conclusion: This case highlights the importance of evaluating for secondary causes for low bone mineral density and often, one may find more than one contributory factor. It also shows that a Z-score of -2.0 could help identify patients with a secondary cause for osteoporosis and those who would especially benefit from a thorough history and examination.

REFERENCES:

[1] Sahin, Idris \& Demir, Cengiz \& Alay, Murat \& Eminbeyli, Lokman. (2011). The Patient Presenting with Renal Failure Due to Multiple Myeloma Associated with Celiac Disease: Case Report. UHOD - Uluslararasi Hematoloji-Onkoloji Dergisi. 21. 10.4999/uhod.09087.

[2] İpek, Belkız \& Aksungar, Fehime \& Tiftikci, Arzu \& Coskun, Abdurrahman \& Serteser, Mustafa \& Unsal, Ibrahim. (2016). A rare association: celiac disease and multiple myeloma in an asymptomatic young patient. Turkish Journal of Biochemistry. 41. 10.1515/tjb-2016-0053.

[3] Swaminathan K, Flynn R, Garton M, Paterson C, Leese G. Search for secondary osteoporosis: are Z scores useful predictors? Postgrad Med J. 2009 Jan;85(999):38-9. doi: 10.1136/pgmj.2007.065748. PMID: 19240287.

Disclosure of Interests: None declared.

DOI: 10.1136/annrheumdis-2021-eular.3594

\section{$\mathrm{AB} 0623$ \\ OSTEOPOROSIS: SCREENING, DIAGNOSIS AND TREATMENT IN TUNISIA: INVENTORY}

S. Jriri ${ }^{1}$, N. El Amri ${ }^{1}$, K. Baccouche ${ }^{1}$, S. Lataoui ${ }^{1}$, H. Zeglaoui ${ }^{1}$, E. Bouajina ${ }^{1}$.

${ }^{1}$ Farhat Hached, rhuematology, sousse, Tunisia
Background: Osteoporosis has become a public health issue due to the increasing number of complications in osteoporotic women in terms of morbidity and mortality.His screening has improved since the refund of the bone densitometry, but prevention, diagnosis and treatment of this pathology remain suboptimal.

Objectives: a qualitative study to understand barriers towards care initiation and levers to improve awareness and management of osteoporosis among general and specialist practitioners.

Methods: The survey was conducted among a random sample of general practitioners and specialists.An anonymous questionnaire was used for this study carried out by mail. It contained 22 questions concerning the socio-demographic characteristics of each practitioner and his patient group, general questions on osteoporosis and questions on the practice in terms of management. The survey lasted about six weeks.

Results: 102 doctors have answered.55,3\% were experienced doctors and $44.7 \%$ were young doctors in training.They were 43 general practitioners, 21 rheumatologists, 15 orthopedists, 13 gynecologists and 10 endocrinologists. The sector of activity in urban and periurban areas was noted in $90 \%$ of casesand $5 \%$ in rural. $43 \%$ exercised a liberal activity and57\% had a hospital-university activity. $60 \%$ of participants believed that osteoporosis is a condition associated with morbi-mortality and $85 \%$ confirmed that it is an underestimated disease. In $72 \%$ of physicians,women over 50 accounted for 25 to $75 \%$ of their female patient base. $86 \%$ of doctors looked for recent information on osteoporosis from medical journals andrecommendations and $11 \%$ from representatives of pharmaceutical companies.In a recently menopausal patient, $68 \%$ of physicians often looked for risk factors for osteoporosis which were: Age in $90 \%$ of cases, early menopause in $84 \%$,presence of a family or personal history of fracture in $65 \%$,a history of prolonged systemic corticosteroid therapy in $46 \%$ ofcases;endocrine pathologies in 29\%;Chronic inflammatory rheumatism was investigated in $19 \%$ of cases,Smoking and alcoholism were investigated in $11 \%$ of cases. The diagnosis of osteoporosis was mentioned in case of bone transparency on standard X-rays in $76 \%$ of cases, a low-energy trauma fracture in $43.5 \%$ and the presence of a risk factor in $35 \%$ of cases. $98 \%$ of responding physicians rely on bone densitometry to make the diagnosis of osteoporosis. $41.2 \%$ of doctors said they were looking for a secondary cause of osteoporosis or a differential diagnosis by requesting a biology. This assessment included:blood phosphocalcic assessment in $88 \%$,vitamin D in $90 \%$,thyroid assessment in $35 \%$,protein electrophoresis in $38 \%$, inflam matory biologic markers in $20 \%$ and immunological factors were requested in $6 \%$ of cases. The choice of anti-osteoporosis treatment depended on the bone densitometry result in $88 \%$ of casesand the presence of a personal history of fractures in $36.5 \%$ of cases.Bisphosphonates were at the top of the therapeutic arsenal of general practitioners and specialists (99.8\%). $100 \%$ of the participants knew the reimbursement criteria for anti-osteoporosis treatment by the national health insurance fund and take them into account when prescribing in $91 \%$ of cases.The duration of a therapeutic sequence varied from one practitioner to another: $13 \%$ of the doctors did not specify it, $45 \%$ treated their patients for five years and $42 \%$ kept the treatment for 3 years. When a fracture occurred during treatment, $64 \%$ of general practitioners had recourse to a rheumatologist, the rest carried out a densitometric reassessment.

Conclusion: The deficits found in the knowledge of both the general practitioners and among others specialists, should be addressed by providing updated information and better awareness of health professionals in order to improve osteoporosis prevention and treatment.

\section{REFERENCES:}

[1] Taylor, J. C., Sterkel, B., Utley, M., Shipley, M., Newman, S., Horton, M. \& Fitz-Clarence, H.2001. Opinions and Experiences in General Practice on Osteoporosis Prevention, Diagnosis and Management. Osteoporosis International, 12(10), 844-848

Disclosure of Interests: None declared.

DOI: 10.1136/annrheumdis-2021-eular.4049

\section{$\mathrm{AB} 0624$ \\ COMPARISON OF DIFFERENT FRAX SCORES WITHOUT BONE MINERAL DENSITY FOR THE EVALUATION OF RISK FRACTURE IN MEXICAN PATIENTS WITH RHEUMATIC DISEASES}

G. Figueroa-Parra ${ }^{1}$, A. Y. Lujano Negrete ${ }^{1}$, R. Moyeda Martinez ${ }^{1}$, C. M. Gamboa-Alonso ${ }^{1}$, D. Á. Galarza-Delgado ${ }^{1}$, C. M. Skinner Taylor ${ }^{1} .{ }^{1}$ Hospital Universitario Dr. José Eleuterio González, Universidad Autónoma de Nuevo León, Servicio de Reumatología, Monterrey, Mexico

Background: Osteoporosis (OP) is characterized by compromised bone strength and deterioration of quality, often leading to fragility fractures(1). Dual-energy $x$-ray absorptiometry (DXA) is the recommended test for OP screening(1). However, there are limitations to perform DXA on all patients, and the clinicians use screening tools to identify those patients with higher risk, like the FRAX score(2). 